\title{
Use of mating disruption for control of New Zealand leafrollers in apple orchards
}

\author{
J.T.S. Walker ${ }^{1}$, D.J. Rogers ${ }^{1}$, P.L. Lo ${ }^{1}$, D.M. Suckling ${ }^{2}$, A.M. El-Sayed ${ }^{2}$, T.M. Fraser ${ }^{3}$ and \\ R.M. Horner ${ }^{4}$ \\ ${ }^{1}$ The New Zealand Institute for Plant \& Food Research Limited, Private Bag 1401, \\ Havelock North, New Zealand \\ ${ }^{2}$ The New Zealand Institute for Plant E Food Research Limited, Private Bag 4704, \\ Christchurch, New Zealand \\ ${ }^{3}$ Fruition Horticulture, PO Box 966, Whakatu, Hawke's Bay, New Zealand \\ ${ }^{4} 571$ Matangi Road, Havelock North, New Zealand \\ Corresponding author: Jim.Walker@plantandfood.co.nz
}

\begin{abstract}
Leafrollers are important pests of apples and infested fruit can result in rejection of export consignments. Leafroller mating disruption using a pheromone blend with activity against three species was examined in 12 Hawke's Bay orchards over two seasons (200910 and 2010-11). Pheromone dispensers (600/ha) and a single insecticide were applied to trees in early November, and subsequent insecticide use was based on leafroller pheromone trapping and thresholds. The pheromone blend substantially suppressed mating of virgin female lightbrown apple moth in treated orchards and reduced male catch in pheromone traps by up to $98 \%$ compared with the season prior to implementation. Insecticide use for leafroller control decreased accordingly, from 2.1-2.7 insecticides per block in 2008/09 to $1.0-1.8$ in 2010/11. Leafroller control using mating disruption was acceptable, fruit damage varied from $0.3 \%$ to $0.16 \%$ and no leafroller larvae were found on fruit in both field assessments and phytosanitary inspections of packed cartons.
\end{abstract}

Keywords New Zealand leafrollers, Tortricidae, mating disruption, apple, insecticide use.

\section{INTRODUCTION}

Codling moth (Cydia pomonella) and several species of leafollers are important pests in New Zealand apple orchards and their presence in harvested fruit can lead to rejection of consignments targeting high value, international markets. Growers following the apple sector's Integrated Fruit Production (IFP) programme use pheromone traps to monitor both codling moth and leafroller activity and respond with insecticides once specified moth activity thresholds are exceeded (Walker et al. 1998). While this approach has been successful in reducing pesticide use, the sector is increasingly aiming for a pest management system that results in either negligible or no insecticide residues on harvested fruit. The need to meet both the phytosanitary requirements in export markets and the demands of customer assurance programmes for minimal pesticide residues, has made the use of codling moth mating disruption an increasingly popular choice for growers.

Single species leafroller mating disruption systems have been evaluated for use in apple production in both New Zealand (Suckling 
\&Shaw 1995) and North America (Knight et al. 1998; Judd \& Gardiner 2008). Extending the use of mating disruption to the complex of three leafroller species present in New Zealand apple orchards provides a real opportunity to further reduce insecticide use required for leafroller control and the likelihood of insecticide residues on harvested fruit. The species of leafrollers commonly encountered in Hawke's Bay apple orchards include the Australian lightbrown apple moth (LBAM) (Epiphyas postvittana), the greenheaded leafroller Planotortrix octo and the brownheaded leafroller Ctenopseustis obliquana. Suckling (unpublished data) re-evaluated disruptive blends for these three leafroller species in a single dispenser based on compounds that had been previously found to reduce pheromone trap catch of all three species by $>90 \%$ and insecticide use by $50 \%$ in trials conducted in Central Otago summerfruit orchards (McLaren et al. 1998). The selected single dispenser blend, originally designed for Central Otago summerfruit (D.M. Suckling, unpublished data), was found to provide only $60-70 \%$ reduction in lightbrown apple moth pheromone trap catches in initial trials conducted in Hawke's Bay apple orchards (Cole et al. 2008). Increasing the quantity of compounds targeting this species in 2009 offered the first potential opportunity for large scale evaluation of leafroller mating disruption in apple orchards for control of all three of the pest leafroller species present in our major apple production regions.

This paper reports on two seasons of trials evaluating the use of leafroller mating disruption in Hawke's Bay apple orchards. In addition, the paper describes results from trials to determine the efficacy of leafroller mating disruption and the development of monitoring systems that might be required to manage any incipient risks of leafroller damage or fruit infestation in pheromone-treated orchards.

\section{METHODS}

\section{Hawke's Bay orchard trials}

Mating disruption trials using a revised 'three New Zealand leafrollers' pheromone blend were conducted on approximately 91 ha of commercial apple production over two seasons. Fifteen orchards participated in 2009-10 and 16 orchards in 2010-11, but this paper reports on mating disruption trials on only 14 orchards (approximately 75 ha) where leafroller mating disruption was deployed in both seasons. Isomate $^{\circledR}$ 'twist-tie' dispensers (Shin-Etsu Fine Chemicals Ltd, Tokyo, Japan) were used in this study. Each dispenser contained $90 \mathrm{mg}$ of a disruptive pheromone blend that included: (E)-11-tetradecenyl acetate (E11-14:Ac), (E,E)9,11-tetradecen-1-yl acetate (E9E11-14:Ac), (n)tetradecyl acetate (n-14:Ac), (Z)-5-tetradecenyl acetate (Z5-14:Ac), (Z)-8-tetradecenyl acetate (Z8-14:Ac) and (Z)-11-tetradecenyl acetate (Z11-14:Ac).

In early November 2010 and again in early November 2011 the dispensers were applied by hand at 600 per ha ( $54 \mathrm{~g}$ ai/ha) close to the tops of trees and this rate was considered sufficient to disrupt mating of these species for at least 4 months. All orchards in this study also deployed codling moth mating disruption in early October in both 2009 and 2010 .

Following IFP pest management guidelines, all growers applied one insecticide in early November targeting control of codling moth: Prodigy $^{\mathrm{TM}}$ (methoxyfenozide) in November 2009 and Altacor ${ }^{\circledR}$ (chlorantraniliprole) in November 2010. Most blocks received no further insecticide applications for leafroller control except the cultivar 'Fuji' where additional insecticide treatments, mostly Proclaim ${ }^{\circledR}$ (emamectin benzoate), were applied to reduce the risk of phytosanitary rejection of these crops from high value Asian markets. Pheromone traps baited with two component LBAM lures (Bellas et al. 1983) (10× or $1.05 \mathrm{mg}$ loading) were operated at approximately one per 2 ha and, in accordance with IFP guidelines, mostly located along the perimeter of pheromone-treated blocks. These were inspected and cleared weekly, with sticky bases changed every 3 weeks and pheromone lures every 6 weeks. Because of the relatively low numbers of native leafrollers encountered in Hawke's Bay orchards, no pheromone traps were 
operated for native species. Crop assessments for leafroller damage and/or larval infestation of fruit were completed within the normal harvest period for each cultivar. These consisted of 100 fruit samples from each of 10 bins per cultivar block.

\section{Virgin female mating}

Suppression of male learoller moth catch in pheromone traps is a measure of communication disruption but only an indirect measure of mating disruption, while use of tethered virgin female moths is a direct measure of its potential effectiveness. Single virgin female LBAM were tethered to the base of delta pheromone trap bodies that served as mating stations. In five pheromone-treated orchards four of these stations were placed on outside trees along each of the perimeters of each orchard while eight traps were placed at least $40 \mathrm{~m}$ internally within each orchard. Tethered virgin female moths were also placed in three non-pheromone treated orchards that had a minimal or no insecticide programme, to determine the frequency of mating in a control group. All virgin female moths were left in the field for 3 days, after which the moths were dissected to determine their mating status. This was completed on two occasions, mid February and early March 2010.

\section{Trap position and cap loading trial}

Leafroller mating disruption suppresses leafroller catch in pheromone traps, but monitoring procedures might still be required to guide supplementary insecticide use within a disruption programme. A replicated trial to determine the influence of trap location, trap height and the pheromone lure loading on leafroller activity in traps was therefore conducted on four of the pheromone-treated orchards. There were four potential monitoring regimes: traps placed within the upper tree canopy ( $\sim 4 \mathrm{~m}$ high) or low within the canopy $(\sim 1.2 \mathrm{~m}$ high $)$ and baited with either a standard LBAM lure $(0.105 \mathrm{mg})$ or a $10 \times$ LBAM lure $(1.05 \mathrm{mg})$. One trap for each regime was then placed on the outside tree along the north, south, east and west perimeters of each of the four orchards. Each regime was also replicated twice internally within each of the orchards with each internal trap location being at least $40 \mathrm{~m}$ from the block perimeter. Trapping commenced on 8-9 March 2010 and all traps were read weekly for 6 weeks. The mean results for each orchard $\times$ location $\times$ height $\times$ strength combination were analysed by ANOVA with a GLM model (GenStat 12.2) using the appropriate blocking structure to determine treatment effects. The data were logarithmically transformed after adding 0.01 to the zero values to stabilise the variance. Model adequacy checks were carried out by examining various plots (scatter, histograms and normal probability) of the residuals. Location data were further separated by LSD $(\mathrm{P}=0.05)$.

\section{RESULTS}

The average pheromone trap catch, insecticide use and leafroller damage across the 12 orchards operating the leafroller mating disruption are shown in Table 1. Results for 2008-09 show the average leafroller (LBAM) pheromone trap catch and insecticide use for leafroller control prior to the implementation of the mating disruption programme. Compared with 2008-09 the average seasonal leafroller trap catch in 200910 and $2010-11$ was reduced by $98 \%$ and $92 \%$ respectively. Total codling moth and leafroller insecticide use on these properties in 200809 was 6.1, 6.0 and 6.9 applications on 'Gala', 'Braeburn' and 'Fuji' cultivars respectively. Most of this insecticide use was associated with codling moth control and some codling mothspecific insecticides were also applied in both 2009-10 and 2010-11. Data for the leafrollerspecific insecticide use are shown in Table 1; use was reduced by approximately one application, from 2.1-2.7 in 2008-09 to 1.0-1.8 applications in 2010-11.

No records of fruit damage were available for the 2008-09 season but all blocks were managed under IFP pest management procedures using codling moth mating disruption while insecticides alone were used for leafroller control (Table 1). Average leafroller damage in 200910 was very low, $0.03 \%$ on 'Gala' and 'Fuji' 
Table 1 The mean cumulative seasonal pheromone catch, mean annual leafroller insecticide use and leafroller damage found at harvest in apple orchard cultivar blocks where leafroller mating disruption was deployed in the 2009-10 and 2010-11 seasons.

\begin{tabular}{|c|c|c|c|c|c|c|}
\hline \multirow[b]{2}{*}{ Season } & \multirow[b]{2}{*}{ Cultivar } & \multicolumn{2}{|c|}{ Mean } & \multicolumn{2}{|c|}{ Leafroller damage } & \multirow{2}{*}{$\begin{array}{c}\text { Number of } \\
\text { blocks }\end{array}$} \\
\hline & & Trap catch & Insecticide use & Mean & Maximum & \\
\hline \multirow[t]{4}{*}{$2008-9$} & 'Gala' & & 2.1 & - & - & 13 \\
\hline & 'Braeburn' & & 2.3 & - & - & 11 \\
\hline & 'Fuji' & & 2.7 & - & - & 6 \\
\hline & Mean & 153.5 & & & & \\
\hline \multirow[t]{4}{*}{$2009-10$} & 'Gala' & & 1.2 & $0.03 \%$ & $0.10 \%$ & 11 \\
\hline & 'Braeburn' & & 1.3 & $0.13 \%$ & $0.70 \%$ & 14 \\
\hline & ‘Fuji’ & & 2.2 & $0.03 \%$ & $0.10 \%$ & 3 \\
\hline & Mean & 2.4 & & $0.08 \%$ & & \\
\hline \multirow[t]{4}{*}{$2010-11$} & 'Gala' & & 1.2 & $0.19 \%$ & $0.90 \%$ & 13 \\
\hline & 'Braeburn' & & 1.0 & $0.16 \%$ & $0.30 \%$ & 11 \\
\hline & 'Fuji' & & 1.8 & $0.17 \%$ & $0.50 \%$ & 6 \\
\hline & Mean & 12.7 & & $0.16 \%$ & & \\
\hline
\end{tabular}

albeit with marginally higher insecticide use on 'Fuji'. Damage was highest on 'Braeburn', a late harvested cultivar that is subjected to greater leafroller activity and therefore damage and/or infestation but even the maximum damage observed did not present any problems for either the grading, packing or export of this crop.

No leafroller larvae were detected in any of the 28,000 and 30,000 fruit that were assessed in field inspections during the 2009-10 and 2010-11 harvests respectively. Furthermore, no fruit from these pheromone-treated blocks were found infested by leafroller larvae in either industry standard packhouse grading and inspection procedures or in subsequent USDA phytosanitary inspections as required for consignments exported to the US market.

\section{Virgin female mating}

Suppression of virgin female moth mating (Table 2 ) is a direct measure of disruption efficacy. No mating of virgin female LBAM occurred on the north and south borders but $27 \%$ of the moths were mated on the western border, suggesting that prevailing westerly winds may have reduced the efficacy of disruption there. No virgin female moths were mated at sites inside the treated orchards (30-40 $\mathrm{m}$ from borders) compared with $67 \%$ mating of moths in untreated orchards.

Table 2 The number and percentage of virgin female lightbrown apple moth mated in internal and perimeter traps on five apple orchards treated with leafroller mating disruption, compared with a control group on untreated orchards.

\begin{tabular}{lccc}
\hline Location & Mated & Total & \% mated \\
\hline Internal & 0 & 49 & 0.0 \\
East perimeter & 1 & 36 & 2.8 \\
North perimeter & 0 & 33 & 0.0 \\
South perimeter & 0 & 33 & 0.0 \\
West perimeter & 9 & 33 & 27.3 \\
\hline Perimeter total & 10 & 134 & 7.5 \\
Control & 34 & 51 & 66.7 \\
\hline
\end{tabular}

\section{Trap position and cap loading trial}

Male lightbrown apple moth catch in pheromone traps baited with $10 \times$ lures on four pheromonetreated orchards is shown in Figure 1. Overall internal traps caught fewer moths than perimeter traps located on the west north, or south, but 
the catch in traps on the east was low and not significantly different to the internal ones $(\mathrm{P}=0.05)$. The highest moth catches occurred in traps along the north and west borders and analysis of wind direction during this period suggested that elevated moth catch on these borders was associated with greater wind runs from westerly and northerly directions. Traps in these perimeter positions would be most likely to have higher catches due to edge effects lowering concentrations in the pheromone cloud.

An effective leafroller monitoring system is required for use with leafroller mating disruption to ensure that mating has been effectively suppressed. The influence of trap height and lure loading on male moth catch in pheromone traps is shown in Figure 2 for traps that were located on the perimeter of pheromone-treated orchards. Low traps caught significantly more moths than high traps $(\mathrm{P}<0.001)$. Likewise, traps baited with $10 \times$ lures caught more than standard lures $(\mathrm{P}<0.001)$. High traps with either $10 \times$ or standard lures and low traps with standard lures caught significantly fewer male moths than low traps baited with $10 \times$ lures. While the catch in all low traps was still variable because of the position/orientation effects on trap catch, those baited with $10 \times$ lures appeared to be a suitable measure of male moth activity suggestive of incomplete disruption of mating at those locations. These results generally concur with the findings of Suckling \& Karg (1996) but a recent discovery of two missing components in the LBAM pheromone (El-Sayed et al. 2011) suggests that this may need revisiting, since the new LBAM pheromone blend is twice as attractive as the two component blend used here.

\section{DISCUSSION}

Leafroller mating disruption dispensers used in this study were developed to prevent mating of three species of leafrollers that can damage or infest untreated fruit. Insecticide use in both seasons of this study was largely restricted to the first 'highly recommended' application for the control of both codling moth and leafrollers, following the IFP guidelines for

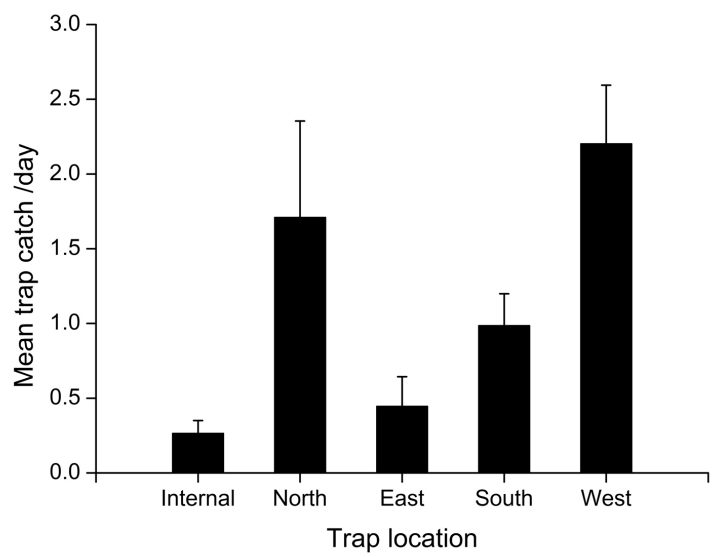

Figure 1 The mean $( \pm$ SEM) number of male lightbrown apple moth caught in internal and perimeter traps baited with $10 \times$ lures operating in a low trap position $(\sim 1.2 \mathrm{~m})$ over a 6 -week trapping period (early March to mid-April 2010) on four apple orchards treated with three New Zealand leafroller mating disruption.

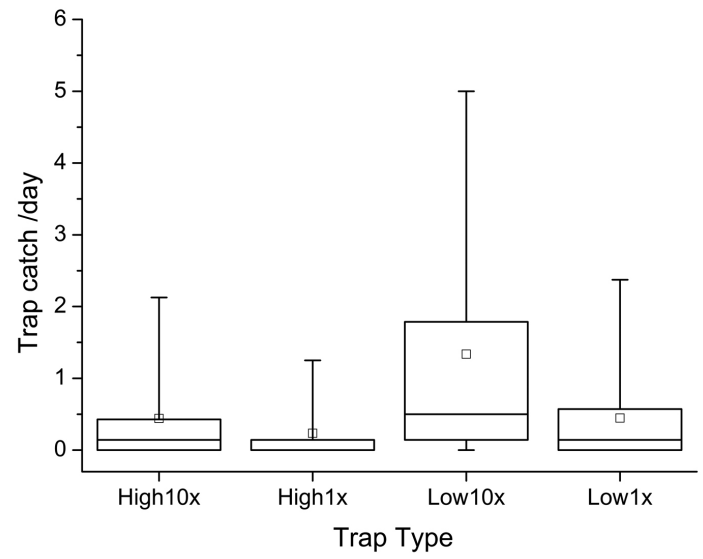

Figure 2 The number of male lightbrown apple moth caught in perimeter traps baited with either $10 \times$ lures or standard lures and placed either low or high (1.2 $\mathrm{m}$ or $4 \mathrm{~m}$ respectively) over a 6-week trapping period (early March and mid April 2010) on four apple orchards treated with three New Zealand leafroller mating disruption. The boxplot is determined by the $25^{\text {th }}$ and $75^{\text {th }}$ percentiles, with the whiskers showing the $5^{\text {th }}$ and $95^{\text {th }}$ percentiles; the horizontal line indicates the median and the mean is represented by a square. 
apples. Leafroller damage in pheromone-treated orchards was acceptably low for both the orchard managers and the packing supply group, albeit marginally higher than might be expected from a pheromone trapping and threshold-based insecticide treatment programme. Leafroller larval infestation is perhaps the most potentially significant phytosanitary risk that threatens the downgrading of export consignments of New Zealand apples. Under the apple sector's IFP guidelines, leafroller infestation of New Zealand apples is a very rare event in consignments of packed fruit submitted for export inspection (one per $>370,000$ apples; J.T.S. Walker, unpublished data). While no larvae were detected in field assessments or phytosanitary inspections of fruit treated with mating disruption, reduced insecticide use might equate to higher larval infestation risk than for fruit treated with insecticides under current IFP guidelines for leafroller control. An assessment of this risk can only be determined by monitoring larval infestation risk during wider adoption of the mating disruption programme. The leafroller monitoring procedures evaluated in this study could be used to determine if intervention with an insecticide is needed to mitigate potential larval fruit infestation risk.

Leafroller activity varies regionally, and orchards in Nelson are subjected to significantly greater LBAM activity than orchards in Hawke's Bay (Suckling et al. 1998), which may explain why preliminary trials with blends targeting multiple species there have not achieved the same degree of male LBAM suppression (P.W. Shaw, Plant \& Food Research, unpublished data) that was reported with LBAM dispensers (Suckling \& Shaw 1995). The pheromone blend used in these trials contains just two components with disruption activity against LBAM. The recent identification of two more components to the LBAM pheromone (El-Sayed et al. 2011) might further enhance the efficacy of this three-species leafroller mating disruption system.

Unlike codling moth mating disruption where moth activity is determined by traps baited with $10 \times$ lures placed in the upper canopy, low placement of traps baited with $10 \times$ lures appears be a suitable method for monitoring LBAM activity in orchards where three New Zealand leafroller mating disruption is deployed. Traps located on the western perimeter of these treated orchards caught more moths and this was probably due to the impact of prevailing winds on the pheromone concentration on western boundaries. Traps placed on perimeters, or along borders where mating disruption is exposed to prevailing winds, are probably the best locations for monitoring the risk of leafroller crop damage or infestation.

Leafroller mating disruption is a complementary control system to codling moth mating disruption, and implementation of both could provide further opportunity to manage both pests and residues, while further reducing insecticide use and residues on harvested fruit (Suckling \& Shaw 1995), and risks of insecticide resistance (Suckling et al. 1990). Residue-risk reduction may well be the single biggest benefit of the programme, as simple reduction in insecticide use alone may be insufficient to justify the cost of three New Zealand leafroller mating disruption. Mating disruption for these pest species is also a highly selective control strategy that mitigates non-target impacts of insecticide use and so maximises the potential for biological control. Future refinements of the leafroller pheromone blend, together with developments in dispenser design and pheromone application technology, will ensure that mating disruption systems play an important role in the future of apple pest management in New Zealand.

\section{ACKNOWLEDGEMENTS}

The authors would like to express their sincere thanks for the support for this project from Pipfruit NZ Inc. and the Ministry of Agriculture and Fisheries' Sustainable Farming Fund and the growers and management of Apollo Pac Ltd., Hawke's Bay, for orchard and packhouse support. We would also like to acknowledge technical and data assistance provided by Lyn Cole, Nandita Sharma and Nicola Park of Plant \& Food Research, Hawke's Bay and Fruition Horticulture's 
Hawke's Bay technical team. This research was also supported in part by The Foundation for Research, Science and Technology, Contract No. CO6X0811 (Sustainable IPM in New Zealand Horticulture).

\section{REFERENCES}

Bellas TE, Bartell RJ, Hill A 1983. Identification of two components of the sex pheromone of the moth, Epiphyas postvittana (Lepidoptera:Tortricidae). Journal of Chemical Ecology 9: 50-512.

Cole LM, Walker JTS, El-Sayed AM, Lo PL, Sharma N2009. A potential mating disruption system for three New Zealand leafroller species. New Zealand Plant Protection 62: 398 (abstract only).

El-Sayed AM, Mitchell VJ, Manning LM, Suckling DM 2011. New sex pheromone blend for the light brown apple moth, Epiphyas postvittana. Journal of Chemical Ecology 37: 640-646 (DOI 10.1007/s10886-011-9964-x).

Judd GJR, Gardiner MGT 2008. Efficacy of Isomate-CM/LR for management of leafrollers by mating disruption in organic apple orchards of western Canada. Journal of Entomological Society of British Columbia 105: 45-59.

Knight AL, Thomson DR, Cockfield SD 1998. Developing mating disruption of obliquebanded leafroller (Lepidoptera: Torticidae) in Washington State. Environmental Entomology 27(5): 10801088.
McLaren GF, FraserJA, SucklingDM 1998. Mating disruption for the control of leafrollers on apricots. New Zealand Journal of Crop and Horticultural Science 26: 259-268.

Suckling DM, Shaw PW, Khoo JGI, Cruickshank $\mathrm{V}$ 1990. Resistance management of lightbrown apple moth, Epiphyas postvittana (Lepidoptera: Tortricidae) by mating disruption. New Zealand Journal of Crop and Horticultural Science 18: 89-98.

Suckling DM, Shaw PW 1995. Large-scale trials of mating disruption of lightbrown apple moth in Nelson, New Zealand. New Zealand Journal of Crop and Horticultural Science 23: 127-137.

Suckling DM, Karg G 1996. Parameters affecting catch of lightbrown apple moth in pheromone-treated orchards. Proceedings of the 49th New Zealand Plant Protection Conference: 319 (abstract only).

Suckling DM, Burnip GM, Walker JTS, Shaw PW, McLaren GF, Howard CR, Lo P, White V, Fraser J 1998. Abundance of leafrollers and their parasitoids on selected host plants in New Zealand. New Zealand Journal of Crop and Horticultural Science 26: 193-203.

Walker JTS, Wearing CH, Bradley SJ, Shaw PW, Burnip GM, Tomkins AR, Richardson CA, Hodson AJ 1998. Integrated Fruit Production (IFP) for New Zealand pipfruit: evaluation of pest management recommendations. Proceedings of the $51^{\text {st }}$ New Zealand Plant Protection Conference: 166-172. 